\title{
TMPROVED FORMABILITY OF ALUMINUM-GERMANIIM NEAR EUTECTIC COMPOSITIONS THROUGH THE APPLICATION OF SUPERPLASTICITY PRINCIPLES
}

Gregory J. Pech

(M. S. thesis)

December 1977

Prepared for the U. S. Department of Energy under Contract W-7405-ENG-48

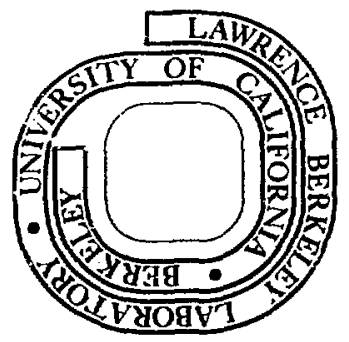


IMPROVED FORMABILITY OF ALUMINUM-GERMANIIM NEAR EUTECTIC COAPOSITIONS THROUGH THE APPLICATION OF SUPFRPLASTICITY PRINCIPLES

\section{TABLE OF CONTENTS}

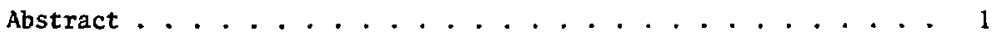

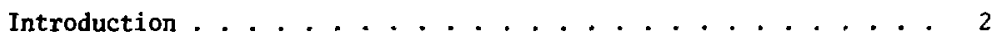

Experimental Methods ................ 5

A. Materials and Equipment ........... . . 5

B. Preparation and Characteristics of the A1-Ge

Compositions .............. 5

1. Metallography ............. 5

2. Microhardness Measurements . . . . . . . 7

C. Mechanical Deformation of the A1-Ge Compositions . . 8

1. Single Reductions . . . . . . . . . . . . . 8

2. Multiple Reductions........... 9

Results and Discussion............... . . 12

A. Superplasticity .............. 12

B. A.1-Ge Microstructures . . . . . . . . . . . 13

C. Mechanical Froperties . . . . . . . . 15

D. Deformation Behavior ............ 15

E. Wire Processing . . . . . . . . . . 17

Sumnary ...................... 19

Future Work ..................... 21

Acknowl edgments . . . . . . . . . . . . 22

Appendix .................. . . 23

References ................. . . 24

Tables .................... . . 26

Figure Captions .................. 29

Figures .................... 32 


\title{
IMPROVED FORMABILITY OF ALUMINUM GERMANIUM NEAR EUTECTIC COMPOSITIONS THROUGH THE APPLICATION \\ OF SUPERPLASTICITY PRINCIPLES \\ Gregory J. Pech \\ Materials and Molecular Research Division \\ Lawrence Berkeley Laboratory \\ and \\ Department of Mechanical Engineering \\ University of California \\ Berkeley, California 94.720
}

\begin{abstract}
ABSTKACT
The 80-20 and 70-30 atomic percent $A 1-G e$ compositions, which are used in the $\mathrm{Nb}_{3}(\mathrm{Al}, \mathrm{Ge})$ superconducting material, were investigated. These alloys are brittle at room temperature, but have been deformed plastically in this study by simulating conditions that have produced superplasticity in similar materials.
\end{abstract}

The microstructure of these Al-Ge compositions was controlled to produce an inherently ductile structure of Ge spheroids dispersed throughout an Al matrix. A very fast cooling rate followed by a short anneal of 7 minutes at $400 \mathrm{C}$ has been found to produce a fine homogenous spheroidal structure in $0.5^{\prime \prime}$ diameter castings.

Vickers microhardness tests were performed on castings of lamellar and fibrous microstructures after anneals at temperatures from 300 to $400 \mathrm{C}$.

The deformation behavior of castings subjected to various conditions is reported. Parameters such as microstructure, temperature, $\frac{8}{z}$ reduction, and anneals were investigated, and the results were used to successfully reduce $A l-G e$ castings to wire. 


\section{INTRODUCTION}

Within the last decade research into the phenomenon of superconductivity has increased substantially. This sudden increase of interest has been due primarily to the discovery of intermetallic compounds with much improved superconducting properties, the large demand for high field magnets, and the recent world energy crisis.

High field superconducting materials are evaluated on three parameters: the critical current density $\left(J_{c}\right)$; the critical magnetic field $\left(\mathrm{H}_{\mathrm{c}}\right)$ in which the superconductor is driven normal; and the critical temperature $\left(\mathrm{T}_{c}\right)$ at which a material becomes superconducting. According to these parameters, one of the best known superconductors is the A-15 phase of the intermetallic compound $\mathrm{Nb}_{3}(\mathrm{Al}, \mathrm{Ge})$. Only the metastable compound $\mathrm{Nb}_{3} \mathrm{Ge}$ is considered to have better properties, but no satisfactory fabrication process has been developed for this compound.

Since the discovery of the $\mathrm{Nb}_{3}\left(\mathrm{Al}_{0.8} \mathrm{Ge}_{0.2}\right)$ superconductor by Matthias, et al., 1 in 1967, many attempt:s have been made to optimize its properties. The highest $T_{c}$ and $H_{c}$ that have been achieved with the superconducting A-15 phase have been $21 \mathrm{~K}$ and $400 \mathrm{kG}$ (at $4.2 \mathrm{~K}$ ). ${ }^{2}$ The largest current density $\left(J_{c}\right)$ in a multifilamentary $\mathrm{Nb}_{3}(A 1, \mathrm{Ge})$ superconductor has been measured in material produced at Lawrence Berkeley Laboratory, on the order of $100,000 \mathrm{amp} / \mathrm{cm}^{2}$ in transverse magnetic fields up to $100 \mathrm{kG} .^{3}$

The superior properties of this superconductor could be used quite effectively in the generation and conservation of energy. Some 
of the important applications are in energy transmission and in superconducting magnets for high energy physics, nuclear fusion, magnetohydrodynamics, and rotating electrical machinery. An economic advantage might also be realized by the use of liquid hydrogen (boiling temp. = $20.3 \mathrm{~K}$ ) as a conlant rather than the commonly used liquid helium (boiling temp. $=4.2 \mathrm{~K}$ ). ${ }^{4}$ The world supply of hydrogen is practically limitless, but helium is in limited supply.

The difficulty of producing the $\mathrm{Nb}_{3}(\mathrm{AI}, \mathrm{Ge})$ supeiconductor in a practical form has been the major obstruction to its use. Both the superconducting A-15 phase and the component aluminum-germanium (A1-Ge) compositions are very brittle. This problem was partially solved by Granda $^{5}$ through the use of powder metallurgy techniques. A method was developed where the $\mathrm{Al}-\mathrm{Ge}$ eutectic was infiltrated into a porous $\mathrm{Nb}$ compact, reduced to a thin tape, and finally subjected to a diffusion heat treatment to form the superconducting A-15 phase in a multifilamentary array. The brittleness of the $\mathrm{Al}-\mathrm{Ge}$ remains as the deterrent to the fabrication of the $\mathrm{Nb}_{3}(\mathrm{Al}, \mathrm{Ge})$ superconductor in the most practicable form: wire.

Although the Al-Ge near-autectic compositions used in this stuperconductor are very brittle, there are reasons to believe that the formability can be improved. It has been reported in the literature on superplasticity ${ }^{6}$ that many binary alloys near eutectic and eutectoid compositions have shown superplastic behavior under certain conditions. Presnyakov and Starikova ${ }^{7}$ (see Underwood ${ }^{8}$ ) have reported a weak superplastic effect in Al-11.3\% $\mathrm{Si}$. This is most encouraging since Al-Si and Al-Ge have similar phase diagrams and morphologies and thus should 
have similar mechanical properties.

In this study superplasticity principles are applied to the $70-30$ (eutectic) and 80-20 atomic percent Al-Ge compositions as an aid in improving the formubility of these alloys. The results of this investigation should prove to be valuable in the production of $\mathrm{Nb}_{3}(\mathrm{Al}, \mathrm{Ge})$ superconducting wire. 


\section{EXPERIMENTAL METHODS}

A. Materials and Equipment

Two compositions of the Al-Ge system were studied: $70-30$ and 80-20 atomic percent Al-Ge, the former being the eutectic composition. These two alloys will be referred to as the '70-30' and '80-20' materials in this report. Both the aluminum and germanium used in these alloys had a purity of $99.999 \%$. Tantalum and hard drawn copper tubes were used to assist mechanical deformation. See Table 1 for details on these materia1s.

Mechanical deformations were performed by two form rolling machines, a swaging machine, and two wire drawing apparatuses. Optical microscopes and a SEM were used to examine microstructures and fracture surfaces. Hardness measurements were taken with a Vickers microhardness tester. The Al-Ge castings were made in vacuum furnaces and annealing was performed in salt bath and air furnaces.

B. Preparation and Characteristics of the AI-Ge Compositions

1. Metal lography

The equilibrion phase diagram of the AI-Ge system is shown in Figure 1. It shows the 70-30 material as the eutectic composition with a eutectic Iiquidus temperature of $424 \mathrm{C}$, and the $80-20$ material as an off-eutectic composition with a liquidus temperature of $500 \mathrm{C}$ and a solidus temperature of $424 \mathrm{C}$.

The most comon structure of the AI-Ge compositions consists of Ge lamellae dispersed through ut an Al matrix. The presence of relatively large Al areas in the 80-20 material is the only structural difference between the two compositions (Figure 2). 
It has been shown $5,9,10$ that the cooling rate has a strong effect on the microstiucture and mechanical properties of the Al-Ge eutectic. As the rate of cooling increases, the Ge lamellae and the spacing between the lamellae become smaller and the hardness increases. It was also found ${ }^{5}$ that if the cooling rate is extremely fast, a very fine fibrous microstructure results which is much harder than the lamellar structure and very brittle.

The 1amellar microstructure of the $70-30$ and $80-20$ materials is shown in Figure 2. These alloys were held at $1000 \mathrm{C}$ for 5 minutes under a vacuum in an Abar furnace. After the furnace was shut off it cooled to a temperature of $424 \mathrm{C}$ in 4.5 minutes and $100 \mathrm{C}$ in 15 minutes.

The fibrous microstructure shown in Figure 3 was obtained by

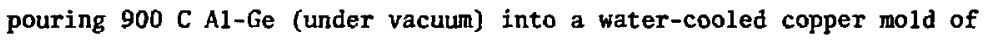
$0.5 "$ ID and $2.5 " \mathrm{OD}$. This rate of cooling is much faster than that producing the Jamellar structure.

It was found that the lamellar and fibrous structures coarsened with time at elevated temperatures. The Ge lamellae and fibers of these two structures changed shapes at temperatures between 300 and $424 \mathrm{C}$, the rate of change being faster with higher temperatures. Figure 4 illustrates the difference in the rate of transformation between the two structures. After 8 hours at $410 \mathrm{C}$ the lamellar structure has coarsened and the lamellae have become segregated. Conversely, the fibrous structure, after 3 minutes at $400 \mathrm{C}$, has changed to a homogeneous semi-spheroidal structure. This fine semi-spheroidal structure is desirable for improvements in ductility.

In order to learn more about the transformation of the lamellar 
and fibrous structures, castings of the $70-30$ composition were annealed for $3,7,15,30,60$, and 120 minutes at temperatures of $300,350,400$, and $415 \mathrm{C}$. This was performed in a salt bath furnace capable of maintaining a constant temperature to within $\pm 1 \mathrm{C}$. In these heat treatments the lamellar structure showed coarsening and a trend toward spheroidization as time and temperature increased. However, a uniform spheroidized structure did not occur under these conditions.

Castings of the fibrous microstructure did attain a spheroida1 or semi-spheroidal structure in all of the anneals. Spheroids of Ge rapidly increased in size with time at temperatures above $400 \mathrm{C}$.

The very quick transformation of the fibrous to the spheroidal microstructure is used in this study to drastically improve the formability of the $70-30$ and $80-20$ Al-Ge materials.

2. Microhardness Measurenients

Vickers pyramid microhardness measurements were made on the $70-3 \mathrm{C}$ castings of fibrous and lamellar microstructure, before and after the anneals described above. A heavy load of $500 \mathrm{gnn}$, was used in all of the measurements so that indentations larger than 50 microns would be made. This size of indentation encompasses a large area of the microstructure rather than the individual components. Other hardness tests wtre not used because it was necessary to distinguish regiors of lamellar and semi-spheroidal structures, both of which often occurred in the same sample. All of the Vickers microhardness tests were performed at room temperature.

The fibrous microstructure was found to be much harder (286.1) than the lame1lar structure (151.9) in the $70-30$ castings. These 
hardnesses dropped quickly in the first few minutes of the heat treatments to values near 100. Figure 5 shows the Vickers microhardness indentations in a 70-30 casting containing both the fibrous and lamellar structures. The fibrous struct'ire is so fine that its components cannot be discerned at this magnification.

C. Mechanical beformation of the Al-Ge Compositions

1. Single Reductions

Form rolling was used to test the ability of the A1-Ge alloys to withstand single reductions under various conditions. Most of the experiments were performed with castings having the fibrous microstructure because this structure transforms readily to the fine semispheroidal structure which is most compatible with superplasticity criteria. 11

A Loma $350,0001 \mathrm{~b} .^{12}$ form rolling mill was used in these tests. The rolling speed in all tests was kept at a constant $30 \mathrm{fpm}$. Only in rolling castings of the lamellar structure was the roliing speed changed $(15,30,45$, and $60 \mathrm{fpm})$, with r.o difference in results.

Because of the brittleness of the 70-30 and 80-20 materials at room temperature, reductions at elevated temperatures were necessary. The temperature at which these materials become ductile was found by form rolling $0.5^{\prime \prime}$ diameter castings to a $50 \%$ reduction in area at temperatures of $250,300,350$, and $400 \mathrm{C}$. In the first tests castings were held at the prescribed rolling temperature 5 minutes prior to roiling. Later it was found that a longer anneal before rolling significantly improved the reduction results.

Once the approximate brittle-to-ductile transition temperature was 
known, $350 \mathrm{C}$, the $0.5^{\prime \prime}$ diameter castings were form rolled to reductions of $32,50,60,67,69$, and $75 \% 13$ at this temperature to learn the materials' deformation capabilities. The 70-30 castings, annealed for 10 minutes at $350 \mathrm{C}$, contained cracks after each of the different reductions. An anneal of one hour at $350 \mathrm{C}$ prior to rolling produced fewer incidents of cracking, but the results were not as good as those of the 80-20 material. The 80-20 castings were annealed for 10 minutes at $350 \mathrm{C}$ prior to rolling. Cracking occurred only in the $32 \%$ reduction.

2. Multiple Reductions

The first attempts to reduce the A.l-Ge alloys to small diameters involved form rolling followed by swaging. A 0.5" Jiameter 80-20 casting with the lamellar structure (Figure 2b) was annealed for 5 minutes at $400 \mathrm{C}$. At $400 \mathrm{C}$ the billet was fed into the 0.25 " form rolling groove, a reduction of $75 \%$. The piece was then clad in copper [0.5" square, $0.25^{\prime \prime}$ bore) and the composite was reduced to a $0.25^{\prime \prime}$ diameter in two form rolling passes, with a 5 minute, $400 \mathrm{C}$ heat treatment before each pass. After cold swa bing the composite to a 0.234 " diameter, the cladding was removed with nitric acid etch. The Al-Ge core was subsequently cold swaged to a $0.022^{\prime \prime}$ diameter wire. Even though this material could withstand the hammering of the rotating swage dies at room temperature, it still snapped in bending. Therefore wire drawing was not attempted. It was encouraging, however, to be able to reduce the 80-20 material by a factor of 517 .

A 0.5 " diameter 70-30 casting with the fibrous microstructure was reduced in the same manner. However, the $\mathrm{Cu}-(\mathrm{AI}-\mathrm{Ge})$ composite was cold swaged to a $0.218^{\prime \prime}$ diameter before the $\mathrm{Cu}$ was removed. The $\mathrm{Al}-\mathrm{Ge}$ core 
was then swaged cold to a $0.115^{\prime \prime}$ diameter, where it began to fracture. Another piece of the same 70-30 casting was clad in copper and reduced through the $0.25^{\prime \prime}$ form roll groove in the same manner as the previous deformations. At this point, instead of swaging, the composite was reduced hot in another smaller form rolling machine (Figure 6), with a 1.5 minute heat treatment at $300 \mathrm{C}$ between each pass. The composite was reduced to a $0.093^{\prime \prime} \times 0.093^{\prime \prime}$ cross section with a $0.051^{\prime \prime} \times 0.056^{\prime \prime}$ Al-Ge core. A nitric acid etch removed the copper, and the Al-Ge was heat treated for 4 hours at $300 \mathrm{C}$ to reduce any strain hardening incurred in these deformations. This Al-Ge core was then swaged cold in 4 passes to a $0.030^{\prime \prime}$ diameter, where it began to break into pieces. An area reduction of a factor of 278 was accomplished in this process.

It was evident from these form rolling and swaging operations that the 80-20 A1-Ge was easier to work than the 70-30 Al-Ge. This was expected because of the smallex volume fraction of the brittle Ge in the 80-20 composition. The 70-30 material could be reduced considerably but could not be worked cold to any large degree. Therefore hot wire drawing was attempted after the form rolling reductions.

A 0.5 " diameter 70-30 casting with the fibrous microstructure was annealed at $350 \mathrm{C}$ for 45 minutes. This allowed the material to be machined, to a $0.420^{\prime \prime}$ diameter, so that it could fit into a copper and tantalum cladding. The Appendix elaborates on the claddings used in this particular operation.

This Cu-Ta-(Al-Ge) composite was form rolled at $350 \mathrm{C}$ from a 0 "594" diameter to a $0.093^{\prime \prime} \times 0.093^{\prime \prime}$ section in several reductions. A hot wire drawing apparatus was then used to reduce the composite to a $0.053^{\prime \prime}$ 
diameter wire. Shown in Figure 7 , the wire drawing facility uses hot oil to bring the wire to temperature before it is pulled through the die. The temperature of the oil was $180 \mathrm{C}$, the highest temperature oil available at LBL. Wire drawing at a higher temperature was wanted, but this temperature proved to be sufficient. 


\section{RESULTS AND DISCUSSION}

\section{A. Superplasticity}

Superplasticity is characterized by low strength and large neckfree reductions, usually at elevated temperatures. ${ }^{6,8,14}$ Examples of superplastic materials and the huge reductions they have undergone are listed in Table 2.

Several explanations for the mechanism(s) responsible for superplasticity have been published (see Davies ${ }^{6}$ ), but have yet received no general acceptance. There is general agreement, however, that certain conditions must be satisfied for superplasticity to occur. Superplastic behavior requires a fine duplex microstructure which remains stable at deformation temperatures, usually greater than half the absolute melting temperature. ${ }^{6,8,14,15}$ These materials are generally highly strain-rate sensitive, with the strain rate sensitivity index exceeding 0.7 in some cases (see Table 2).

Presnyakov (see Underwood ${ }^{8}$ ) has reported a weak superplastic effect in Al-11.3 at\% $\mathrm{Si}$ : maximum elongation $=117 \%$. Since Al-Si and Al-Ge have similar phase diagrams and morphologies, and $\mathrm{Ge}$ and $\mathrm{Si}$ have the same crystal structure (diamond), these two alloys should have similar mechanical properties. Therefore certain Al-Ge compositions may exhibit superplastic behavior.

This investigation was not aimed at producing superplasticity in the $70-30$ and $80-20$ at. $: A 1-G e$ alloys. The purpose was to apply superplasticity principles to improve the formability of these inherently brittle materials such that they could withstand many reductions in the production of wire. 
B. Al-Ge Microstructures

In accordance with superplasticity criteria, a fine microstructure is desired in the Al-Ge materials under study. It is generally found that the faster the solidification rate the finer is the microstructure, ${ }^{16}$ and it has been shown $5,9,10$ that the $A 1-G e$ eutectic is no exception. If the solidification rate is extremely fast, a very fine fibrous structure quite different from the lamellar structure is obtained (Figure 3). A homogeneous fibrous microstructure was obtained in $0.5^{\prime \prime}$ diameter (12" long) castings poured at $900 \mathrm{C}$ into a watercooled copper mold. When poured at $950 \mathrm{C}$ and above, arcas of the lamellar structure formed toward the center of the casting--these areas increasing in size toward the top of the casting. This is most likely due to the mold's inability to quickly dissipas the larger amounts of energy, resulting in a slower rate of cooling.

To exemplify the brittleness of the fibrous microstructure, a $0.5 "$ diameter, 12" long 70-30 casting fractured into six pieces when accidentally dropped from waist height onto the floor. In fact, both cast microstructures are brittle, but can be transformed into an inherently ductile spheroidal structure.

Heat treatments up to 8 hours at $410 \mathrm{C}$ did not completely spheroidize the lamellar structure, but significantly coarsened it (Figure 4b). This lamcllar structure was transformed to spheroids by a combination of heat and plastic deformation. A 0.5" diameter 80-20 casting was form rolled at $375 \mathrm{C}$ to a $32 \%$ reduction. This broke up the network of Ge lamellae in certain outer portions of the cross section but left the center virtually unchanged, as shown in Figure 8 . A post heat 
treatment of 1 hour at $410 \mathrm{C}$ spheroidized the broken pieces of Ge (Figure 8d). A $50 \%$ form rolling reduction was found to be necessary to fracture the Ge lamellae throughout the cross-section.

Only a short heat treatment is required to transform the fibrous cast microstructure to a semi-spheroidal structure, This semi-spheroidal structure is much finer than that obtained from lamellar castings (compare Figures $4 d$ and $8 d$ ) and once this structure is obtained it remains relatively stable at temperatures up to $400 \mathrm{C}$. Above $400 \mathrm{C}$ the rate of spheroidization increases substantially. Figures 9 and 10 show the microstructures of the 70-30 Al-Ge after heat treatmerts at $300,350,400$, and $415 \mathrm{C}$. At $400 \mathrm{C}$ the trend to coarsen is more noticeable and at $415 \mathrm{C}$ there is a rapid agglomeration of $\mathrm{Ge}$. This behavior is similar to the spheroidization of pearlite plates at temperatures approaching the eutectoid, to form what is known as spheroidite. The driving force of this transformation is the reduction of the system's total interfacial energy. 17

The deformation behavior of the fine scmi-spheroidul structure is indicated by the amount of cracking around the : identation of a Vickers pyramid microhardness test. This is shown in Figure 11 , along with the hardness test results in a lamellar structure. These samples received the same anneal ( 1 hour at $400 \mathrm{C}$ ) prior to this hardness test. Five indentations in each sample produced identical results.

These microstructure results show that the semi-spheroidal structure obtained from the fibrous cast structure has the most potential for improving the ductility of the Al-Ge compositions. Not only is this microstructure very fine and stable at temperatures below $400 \mathrm{C}$, it is 
also quite easy to obtain.

\section{Mechanical Properties}

The results of the Vickers ticrohardness tests on the annealed 70-30 castings are shown graphically in Figures 12 and 13 , and tabulated in Table 3. The hardness of the cast fibrous structure $(286.1)$ is greater than the cast lamellar structure (151.9), but within minutes both rapidly decrease to similar hardnesses (about 110) and then stabilize.

A sensitivity to the annealing temperature is clearly shown in the hardness of the fibrous structure. As the temperature was increased from $300 \mathrm{C}$ to $400 \mathrm{C}$ the material became softer in a shorter perion of time. In 60 minutes the hardness stabilized, decreasing only slightly as time increased.

The hardness of the Iamellar structure was less sensitive to variations in temperature. This behavior was also seen in the structure itself: in contrast to the fibrous structure, the lamellar structure did not change appreciably under the conditions of these anneals. However, the hardness of castings with the lamellar structure stabilized sooner than the fibrous.

Although both types of castings softened to approximately the same values, the significant difference was in the structural transitions. This is related to the structures" ability to minimize its total interfacial energy.

D. Deformation Behavior

After the microstructural characteristics of the $70-30$ and $80-20$ at. $\mathrm{Al-Ge}$ alloys were known, it was interesting to learn the deformation 
behavior of these materials at elevated temperatures. The lowest temperature at which these materials could be successfully deformed to a $50 \%$ reduction in area was determined.

Cracking occurred at all of the testing temperatures in the 70-30 material with the fibrous microstructure. However, at $350 \mathrm{C}$ and $400 \mathrm{C}$ the cracks were very small, as shown in Figure 14. Below $350 \mathrm{C}$ the cracking has destroyed the material for all practicability. These castings were held at the rolling temperature 5 minutes before form ro11ing.

A heat treatment of 1 hour at $350 \mathrm{C}$ allowed this $70-30$ material to be reduced at $250 \mathrm{C}$ with much better results (Figure 14). This is not surprising, considering the structural and microhardness results this heat treatment produces.

A cladding of $\mathrm{Cu}$ and Ta allowed the 70-30 casting with the fibrous structure to be reduced at $350 \mathrm{C}$ without cracking or surface flaws. Claddings and anneals were thus used (quite successfully) in multiple reductions of this material.

Castings with the lamellar structure were also tested. At all of the temperatures $(250-400 \mathrm{C})$ the result was the same: a cracked specimen almost identical to that of the $300 \mathrm{C}$ deformation shown in Figure 14.

The 80-20 Al-Ge with the fibrous microstructure reduces nicely at temperatures of $350 \mathrm{C}$ and greater. See Figure 15. Below $350 \mathrm{C}$ cracking is a problem, but a heat treatment of 30 minutes at $330 \mathrm{C}$ allowed this material to be rolled at $250 \mathrm{C}$ with no cracking whatsoever. This improved behavior is again attributed to the material's softening and 
microstructural transformation produced by the anneal.

Nt a temperature of $350 \mathrm{C}$, both compositions with the fibrous microstructure were form rolled to various reductions to learn the alloys' deformation capabilities. The 70-30 material was annealed for 1 hour at $350 \mathrm{C}$ and the 80-20 material was annealed 10 minutes at 350 C prior to rolling.

In single reductions from 50 to $69 \%$ the $70-30$ alloy showed minor cracking. See Figure 16. Large cracks occlirred in the $32 \%$ reduction and no cracks occurred in the $75^{\circ}$ reduction. The absence of cracks in the larger reduction is puzzling, but may be a result of existing cracks sealed shut as they passed through the rolls. Regardless of explanations, the $75 \%$ form rolling reduction is not recommended due to the huge material loss in the form of fins. The cladding technique seems to be the best method for form rolling the 70-30 Al-Ge.

In single reductions of 50 to $75 \%$ the $80-20$ material deformed without cracking (Figure 17). Cracking was seen, however, in the $32 \%$ reduction. This behavior shows a trend of cracking at small reductions but not at large reductions. Therefore it is recommended that a cladding be used to facilitate wire drawing, where reductions tend to be small.

E. Wire Processing

The information produced from the previous experiments was used to reduce both the $70-30$ and $80-20$ alloys to wire from castings of $0.5^{\prime \prime}$ diameter. Reductions were performed at elevated temperatures and facilitated by the use of claddings.

The 80-20 material with the lamellar microstructure was successfully 
reduced from a $0.5^{\prime \prime}$ to a $0.022^{\prime \prime}$ diameter by hot form rolling followed by cold swaging. The latter diameter represents the limit to which this particular wire could be cold swaged, for subsequent swages produced multiple fracturing. The 70-30 material with the semi-spheroidal microstructure behaved in the sane manner, but fractured at a larger diameter (0.030") during cold swaging. This fracturing is most likely a strain-hardening effect, for it is generally true that alloys strainharden more than pure metals. ${ }^{17}$ Dorn, et al., ${ }^{18}$ reported that the addition of only a small amount $(0.082$ at. $\%)$ of Ge to pure Al resulted in an increased strain-hardening effect at $22 \mathrm{C}$.

To minimize strain-hardening, the cold swaging operation was replaced with hot wire drawing. Therefore reduction was by form rolling at $350 \mathrm{C}$ followed by wire drawing at $180 \mathrm{C} .^{19}$ Copper and tantalum were used as cladding materials, which were not removed until the reductions were completer.

This process allowed the $70-30$ material to be reduced from a $0.420^{\prime \prime}$ diameter to a $0.020^{\prime \prime}$ diameter wire, shown in Figure 18 . At room temperature the $A 1-G e$ is still relatively brittle, but the small diameter allows it to be handled--on the same principle as glass fibers. $\Lambda 2 \mathrm{ft}$. 1ength of this wire was produced, but the absence of cracking in both the form rolling and wire drawing operations indicates that much greater lengths are possible. 


\section{SUMAARY}

The formability of the inherently brittle $70-30$ and $80-20$ atomic percent Al-Ge alloys has been significantly improved through the application of superplasticity principles. Superplastic behavior usually r:4 ires a fine duplex microstructure which is stable at deformation tempuratures, commonly greater than one half the absolute melting temperatures.

A fine duplex microstructure was obtained in these Al-Ge compositions by short anneals of castings with a fibrous microstructure. The fibrous structure was obtained by superheating the $\mathrm{Al}-\mathrm{Ge}$ t. $900 \mathrm{C}$ and then rapidy cooling the melt by casting in a water-cooled copper mold. A subsequent anneal of 7 minutes at $400 \mathrm{C}$ transformed the brittle fibrous microstructure (Vickers $=286$ ) to a much softer semi-spheroidal structure (Vickers $=107)$. This semi-spheroidal structure is much finer than the common lamellar structure characteristic of these alloys, and was found to be quite stable at temperatures below $400 \mathrm{C}$.

In form rolling reductions at elevated temperatures the $\mathrm{Al}-\mathrm{Ge}$ specimens with the semi-spheroidal structure had fewer incidents of cracking than specimens with the lamellar structure. Cracking was eliminated in the 70-30 material through the use of claddings. Although cracking was not a problem with the $80-20$ material, claddings were used to facilitate wire drawing.

With the aid of a copper and tantalum cladding, the 70-30 Al-Ge alloy was successfully reduced from a $0.420^{\prime \prime}$ diameter to a $0.020^{\prime \prime}$ diameter wire. Reductions were by hot form rolling followed by hot wire drawing at temperatures not exceeding $350 \mathrm{C}$. The microstructure 
was semi-spheroidal.

The objective of this investigation was not to produce superplasticity in the Al-Ge materials, but was to produce ductility in these brittle materials with the aid of superplasticity concepts. Figure 19 dramatizes the meeting of this objective by comparing a $50 \%$ flat rolled reduction of the 70-30 material to a wire of the same composition that has been reduced in diameter (area) by a factor of 441 . This result should be valuable toward the fabrication of the $\mathrm{Nb}_{3}(\mathrm{Al}, \mathrm{Ge})$ superconducting wire. 
FUTURE WORK

Now that the Al-Ge ductility problem has been solved, it follows that the fabrication of $\mathrm{Nb}_{3}(\mathrm{Al}, \mathrm{Ge})$ superconducting wire should be an easier task. Two methods immediately show potential for this purpose: (1) the infiltration process; ${ }^{2,5}$ and (2) the Nb-Ti process. ${ }^{20,21}$

(1) The infiltration process uses powder metallurgy techniques to produce a multifilamentary tape. Niobium powder is compacted and sintered such that an interconnected network of porosity results (about 25\%). Liquid $A 1-G e$ is then infiltrated into the compact, filling the pores. This composite is flat rolled to its final thickness and then diffusion heat treated to form the brittle superconducting phase.

In order to produce wire, the $\mathrm{Nb}$ compact would be made in a cylindrical shape. After infiltration, hot form rolling or extrusion at $350 \mathrm{C}$ followed by hot wire drawing would replace the flat rolling operation. Wire drawing would probably have to be facilitated hy a cladding, which could be later removed.

(2) The Nb-Ti process could be altered slightly to produce a multifilamentary array of Al-Ge in a Nb matrix. The conceptual process is illustrated in Figure 20. The casting of Al-Ge should have the fibrous microstructure so that an anneal of 10 minutes at $400 \mathrm{C}$ would produce the spheroidal microstructure. Deformations should be performed at temperatures between 300 and $400 \mathrm{C}$. 


\section{ACKNOWLEDGMENTS}

The author would like to sincerely thank Dr. Milton R. Pickus for his guidance and constructive critiques throughout this research. Very special thanks to Dr. John ling-Fai Wang for his encouragement, guidance, and fruitful discussions on superplasticity and the Al-Ge system.

Thanks to Mr. John T. Holtuis for his assistance and instruction in the mechanical deformation processes, and to Mr. John A. Jacobsen for his general technical assistance.

This work was supported by the Division of Materials Sciences, Office of Basic Energy Sciences, U.S. Department of Energy. 


\section{APPENDIX}

-Details of 70-30\% A1-Ge Wire-Drawing Process-

A $0.5 "$ diameter 70-30 casting with the fibrous microstructure was annc I u $350 \mathrm{C}$ for 45 minutes. This istuned the material to be machined, to a $0.420^{\prime \prime}$ diameter. A copper tube $\left(0.625^{\prime \prime} \mathrm{OD}, 0.035^{\prime \prime}\right.$ wall) was swaged to $0.594^{\prime \prime}$ OD to fit tightly over a tantalum tube $\left(0.500^{\prime \prime} \mathrm{OD}\right.$, $0.020^{\prime \prime}$ wa11). The diameter of the Ta tube was reduced to $0.475^{\prime \prime}$ by this swaging. The $0.420^{\prime \prime} \mathrm{A} 1-\mathrm{Ge}$ was inserted as the core to this composite.

This $\mathrm{Cu}-\mathrm{Ta}-(\mathrm{Al}-\mathrm{Ge})$ composite was heat treated for 1 hour at $300 \mathrm{C}$ ard then form rolled at $350 \mathrm{C}$ to a $0.25^{\prime \prime}$ diameter, in 4 passes.

At this point the $\mathrm{Cu}$ cladding was too thin, and was romoved. Th: Ta was also very thin, so the $0.2 C^{n \prime \prime} \mathrm{Ta}-(\mathrm{Al}-\mathrm{Ge})$ core was inserted in another Ta tube $\left(0.250^{\prime \prime} O D, 0.020^{\prime \prime}\right.$ wal1). This composite was then clad in $\mathrm{Cu}\left(0.375^{\prime \prime}\right.$ square, $0.250^{\prime \prime}$ bore).

This assembly was again form rolled at $350 \mathrm{C}$, to a $0.093^{\prime \prime} \mathrm{x}$ $0.093^{\prime \prime}$ section.

Again the copper cladding was removed, ard replaced with a new copper tube $\left(0.188^{\prime \prime} \mathrm{OD}, 0.035^{\prime \prime}\right.$ wall $)$ which was swaged to $0.109^{\prime \prime}$, over the $0.060^{\prime \prime} \mathrm{Ta}-\mathrm{Al}-\mathrm{Ge}$ ) core. This assembly was hot wire drawn (180 C) to a diameter of $0.053^{\prime \prime}$ in an apparatus shown in Figure 7 . The $\mathrm{Al}-\mathrm{Ge}$ eutectic core was reduced from a $0.420^{\prime \prime}$ to a $0.020^{\prime \prime}$ diameter in this process without any complications (except for the tedious cladding changes). See Figure 18. 


\section{REFERENCES}

1. B. T. Matthias, T. H. Geballe, L. D. Longinotti, E. Corenzwit, G. W. Hu11, R. H. Willens, J. P. Maita, Science 156, 645 (1967).

2. M. R. Pickus and J. L-F. Hang, Paper presented at the Internationa1 P/M Conf. 1976, LBL 5121, May 1976.

3. M. R. Pickus, M. P. Dariel, J. T. Holtuis, J. L-F. Wang, and J. Granda, App1. Phys. Letters, 29 12, 810 (1976).

4. J. Ling-Fai Wang, Private conversation.

5. J. J. Granda, M. S. Thesis, LBL-5772, December 1976.

6. G. J. Davies, J. W. Edington, C. P. Cutler, and K. A. Padmanabhan, J. Mat. Science, 5, 1091 (1970).

7. A. A. Presnyakov and G. V. Starikova, IzV. Akad. Nauk SSSR, Otde1. Tekh. Nauk, 1, 75 (1959).

8. E. E. Underwood, J. Metals, 914 (December 1962).

9. A. He1lawe11, Trans. Met. Soc. AIME, 239, 1049 (1967).

10. P. Ramachandrarao, M. G. Scott, and G. A. Chadwick, Phil. Mag., 25, 961 (1972).

11. Superplasticity criteria are discussed in the RESULTS and DISCUSSION section.

12. A $350,000 \mathrm{lb}$. force is necessary to separate the bearings containing the rolls.

13. These are the reductions obtained by passing a $0.5^{\prime \prime}$ diameter ingot through successive grooves of the Loma form rolling mill.

14. W. Johnson and P. B. Me1lor, Engineering Plasticity, Van Nostrand Reinhold Company LTD, 1973. 
15. V. A. Likhachev, M. M. Myshlyaer, S, S. Olevskii, and T. N. Chuchman, Acta Met., 22, 829 (1974).

16. A. L. Ruoff, Introduction to Materials Science, Prentice-Hall, 1972.

17. C. E. Birchena11, Physical Metallurgy, McGraw-Hil1, 1959.

18. J. E. Dorn, P. Pietrokowsky, and T. E. Tietz, Trans. AIME, I88, $933(1950)$.

19. This is the maximum temperature of the oil used in the hot-wire drawing apparatus (Figure 7).

20. D. F. Neal, A. C. Barket, A. Woocock, and J. A. F. Gidley, Acta Met., 19, $143(1971)$.

21. D. A. Colling, T. A. de Winter, W. K. McDonald, and W. C. Turner, IEEE Trans. Mag., MAG-13 1, 848 (1977). 
26

Table 1: Materials Used.

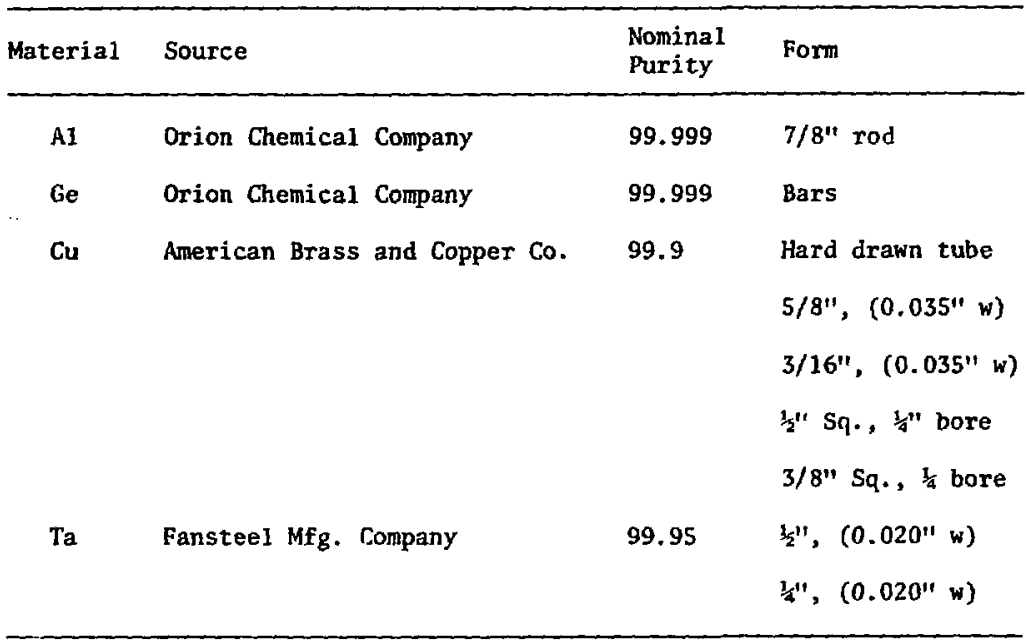


Table II: Superplastic Materials. ${ }^{6}$

\begin{tabular}{|c|c|c|c|}
\hline \multirow{2}{*}{ Materials } & \multicolumn{2}{|c|}{ Reported Maximum Values } & \multirow{2}{*}{$\begin{array}{l}\text { Temperature Range } \\
\text { (C) }\end{array}$} \\
\hline & $m$ * & olongation & \\
\hline Cd- $\mathrm{Zn}$ eutectic & - & 400 & 20 \\
\hline $\mathrm{Sn}-\mathrm{Pb}$ eutectic & 0.6 & 700 & 20 \\
\hline Sn-Bi eutectic & 0.2 & 1950 & 20 \\
\hline $\begin{array}{l}\mathrm{Zn}-4.9: \mathrm{Al} \\
\text { eutectic }\end{array}$ & 0.5 & 300 & $200-260$ \\
\hline $\begin{array}{l}\mathrm{Zn}-22 \div \mathrm{Al} \\
\text { eutectoid }\end{array}$ & 0.7 & 1500 & $200-300$ \\
\hline Mg-Al eutectic & 0.8 & 2100 & $350-400$ \\
\hline $\mathrm{Al}-\mathrm{Cu}$ eutectic & 0.9 & 500 & $440-520$ \\
\hline
\end{tabular}

${ }^{*} \mathrm{~m}$ is the strain rate sensitivity index. 
Table III: Vickers Microhardness of A1-Ge Eutectic After Various Annea 1s *

\begin{tabular}{|c|c|c|c|c|}
\hline $\begin{array}{l}\text { Beginning } \\
\text { Structure }\end{array}$ & $\begin{array}{c}\text { Temperature } \\
\text { (C) }\end{array}$ & Time (min.) & $\begin{array}{c}\text { Vickers } \\
x\end{array}$ & $\underset{\sigma}{\text { Microhardness }}$ \\
\hline Fibrous & 400 & $\begin{array}{r}3 \\
7 \\
15 \\
30 \\
60 \\
120\end{array}$ & $\begin{array}{l}112.9 \\
106.5 \\
105.6 \\
106.5 \\
101.3 \\
100.7\end{array}$ & $\begin{array}{r}3.03 \\
3.41 \\
3.17 \\
4.74 \\
2.97 \\
5.58\end{array}$ \\
\hline Fibrous & 350 & $\begin{array}{r}3 \\
7 \\
15 \\
30 \\
60 \\
120\end{array}$ & $\begin{array}{l}129.3 \\
123.7 \\
116.5 \\
109.8 \\
109.2 \\
100.2\end{array}$ & $\begin{array}{l}7.18 \\
3.92 \\
3.47 \\
3.33 \\
4.61 \\
4.29\end{array}$ \\
\hline Fibrous & 300 & $\begin{array}{r}3 \\
7 \\
15 \\
30 \\
60 \\
120\end{array}$ & $\begin{array}{l}198.0 \\
156.9 \\
126.8 \\
120.5 \\
113.3 \\
113.2\end{array}$ & $\begin{array}{r}22.54 \\
14.90 \\
5.92 \\
7.40 \\
7.26 \\
6.78\end{array}$ \\
\hline Lamellar & 400 & $\begin{array}{r}3 \\
7 \\
15 \\
30 \\
60 \\
120\end{array}$ & $\begin{array}{r}110.7 \\
105.1 \\
105.6 \\
104.3 \\
102.2 \\
98.5\end{array}$ & $\begin{array}{r}10.30 \\
6.41 \\
11.21 \\
11.62 \\
12.67 \\
7.43\end{array}$ \\
\hline Lema 11 ar & 350 & $\begin{array}{r}3 \\
7 \\
15 \\
30 \\
60 \\
120\end{array}$ & $\begin{array}{r}112.5 \\
112.0 \\
109.0 \\
106.9 \\
109.0 \\
99.4\end{array}$ & $\begin{array}{l}7.41 \\
8.88 \\
9.46 \\
5.09 \\
4.24 \\
7.16\end{array}$ \\
\hline Lame1lar & 300 & $\begin{array}{r}3 \\
7 \\
15 \\
30 \\
60 \\
120\end{array}$ & $\begin{array}{l}120.4 \\
113.2 \\
103.7 \\
114.8 \\
103.6 \\
108.7\end{array}$ & $\begin{array}{l}9.64 \\
5.43 \\
5.28 \\
5.29 \\
7.97 \\
7.00\end{array}$ \\
\hline
\end{tabular}

*Five indentations were made in each sample: $x=$ average, and $\sigma=$ standard deviation of these five readings. 


\section{FIGURE CAPTIONS}

Fig. 1 Al-Ge Equilibrium Phase Diagram

Fig. 2 Typical lamellar microstructure of the Al-Ge alloys; (a) $70-30$ at. $\mathrm{Al}-\mathrm{Ge}$, (b) $80-20$ at. $\% \mathrm{Al}-\mathrm{Ge}$.

Fig. 3 Fibrous microstructure of Al-Ge castings; (a) 70-30 at. : Al-Ge, (b) $80-20$ at. \& Al-Ge.

Fig. 4 Microstructural transformations of the lamellar and fibrous microstructures produced by anneals; (a) lame1lar structure before anneal, (b) lamellar structure after 8 hours at $410 \mathrm{C}$, (c) fibrous structure before anneal, (d) fibrous structure after 3 minutes at $400 \mathrm{C}$ (semi-spheroidal).

Fig. 5 70-30 at. $:$ Al-Ge casting with Vickers pyramid indentations in lamellar and fibrous regions.

Fig. 6 Form rolling machine used in reducing material with less than a $0.25^{\prime \prime} \times 0.25^{\prime \prime}$ cross-section.

Fig. 7 Hot-wire-drawing apparatus: (1) frame, (2) die, (3) wiresubmersion mechanism, (4) wire, (5) hot oil, (6) heating element.

Fig. 8 Transformation of the lamellar to spheroidal microstructure in 80-20 at. : Al-Ge; (a) initial structure, (b) outer portion of casting after a 32\% reduction, (c) center of the same casting after $32 \%$ reduction, (d) outer portion of reduced material after heat treatment of 1 hour at $410 \mathrm{C}$. 
Fig. 9 Semi-spheroidal structure obtained by a 7 minute anneal of 70-30 castings with the fibrous microstructure: (a) $415 \mathrm{C}$, (b) $400 \mathrm{C}$, (c) $350 \mathrm{C}$, (d) $300 \mathrm{C}$.

Fig. 10 Semi-spheroidal structure obtained by a 120 minute anneal of 70-30 castings with the fibrous microstructure: (a) $4 \mathrm{IS} \mathrm{C}$, (b) $400 \mathrm{C}$, (c) $350 \mathrm{C}$, (d) $300 \mathrm{C}$.

Fig. 11 Cracking around Vickers microhardness indentations in annealed (1 h. $400 \mathrm{C}) 70-30 \mathrm{Al-Ge;} \mathrm{(a)} \mathrm{lamellar} \mathrm{structure,} \mathrm{(b)} \mathrm{spher-}$ oidal structure.

Fig. 12 Vickers microhardness of annealed 70-30 at. with the lamellar microstructure.

Fig. 13 Vickers microhardness of annealed 70-30 at. with the fibrous microstructure.

Fig. 14 70-30 at. $\mathrm{Al}-\mathrm{Ge}$, with fibrous microstructure, form rolled at various temperatures to a $50 \%$ reduction.

Fig. 15 80-20 at. $\mathrm{Al}-\mathrm{Ge}$, with fibrous microstructure, form rolled at various temperatures to a $50 \%$ reduction.

Fig. 16 70-30 at. : A1-Ge with fibrous microstructure, form rolled at $350 \mathrm{C}$ to various reductions.

Fig. 17 80-20 at. $:$ Al-Ge with fibrous microstructure, form rolled at $350 \mathrm{C}$ to various reductions.

Fig. $18 \mathrm{Cu}-\mathrm{Ta}-(70-30)$ at. $\% \mathrm{Al}-\mathrm{Ge})$ wire produced by form rolling at 350 $\mathrm{C}$ followed by wire drawing at $180 \mathrm{C}$; (a) longitudinal section, (b) transverse section. 
Fig. 19 70-30 at. $\quad$ A1-Ge: Center pieces are a result of a $50 \%$ flatrolling reduction at room temperature, and wire is that of Figure 18 with copper removed.

Fig. 20 Conceptual fabrication of multifilamentary $\mathrm{Nb}-(\mathrm{Al}-\mathrm{Ge})$ wire. 


\section{Al-Ge Aluminum-Germanium}

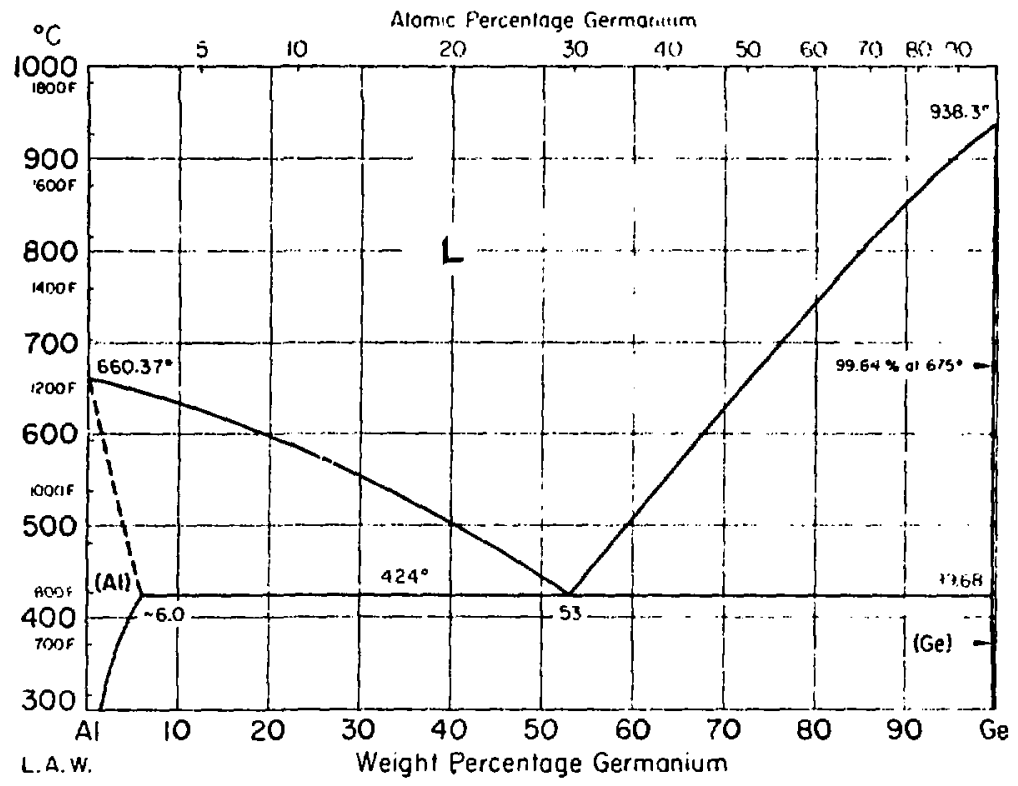

XBL 767-B550

Fig. 1 

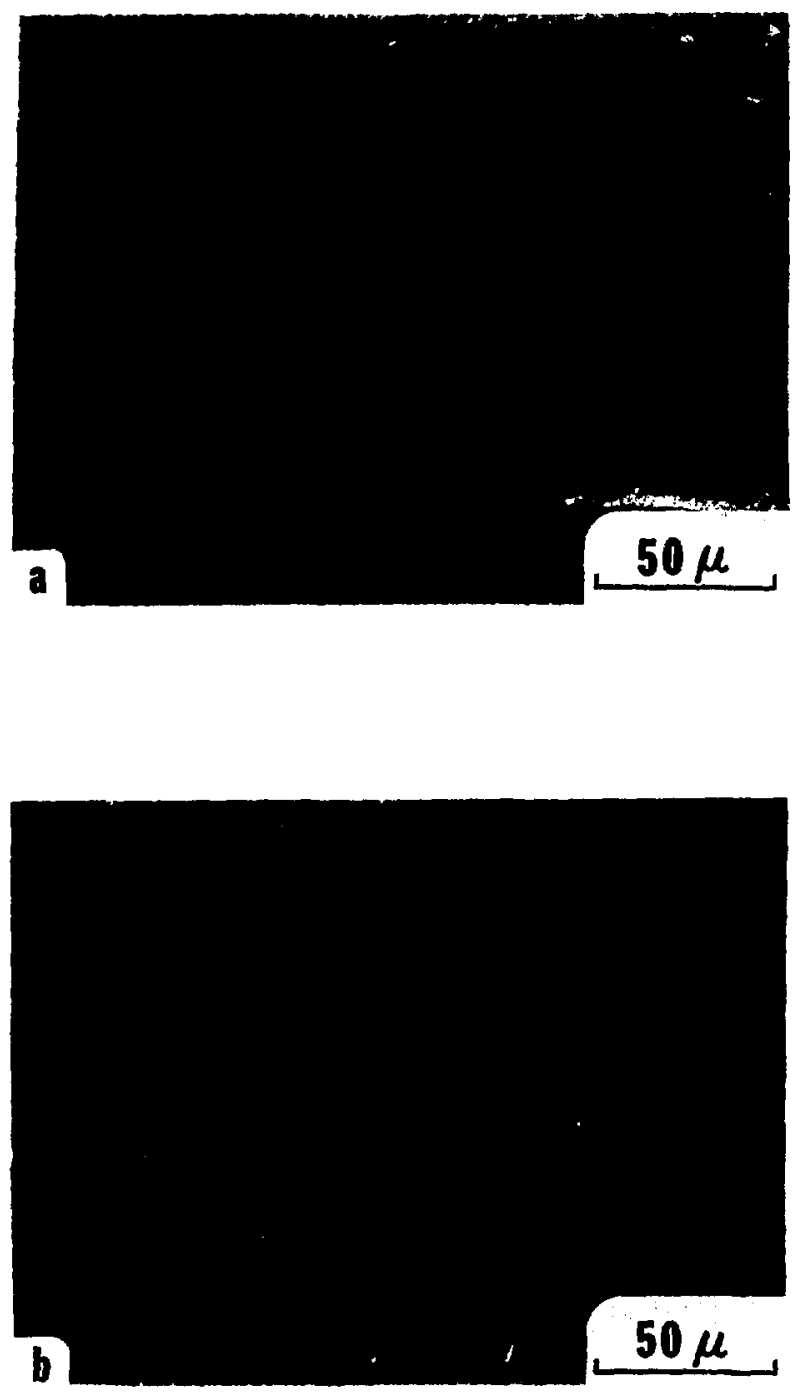

XBB 770-12003

Fig. 2 

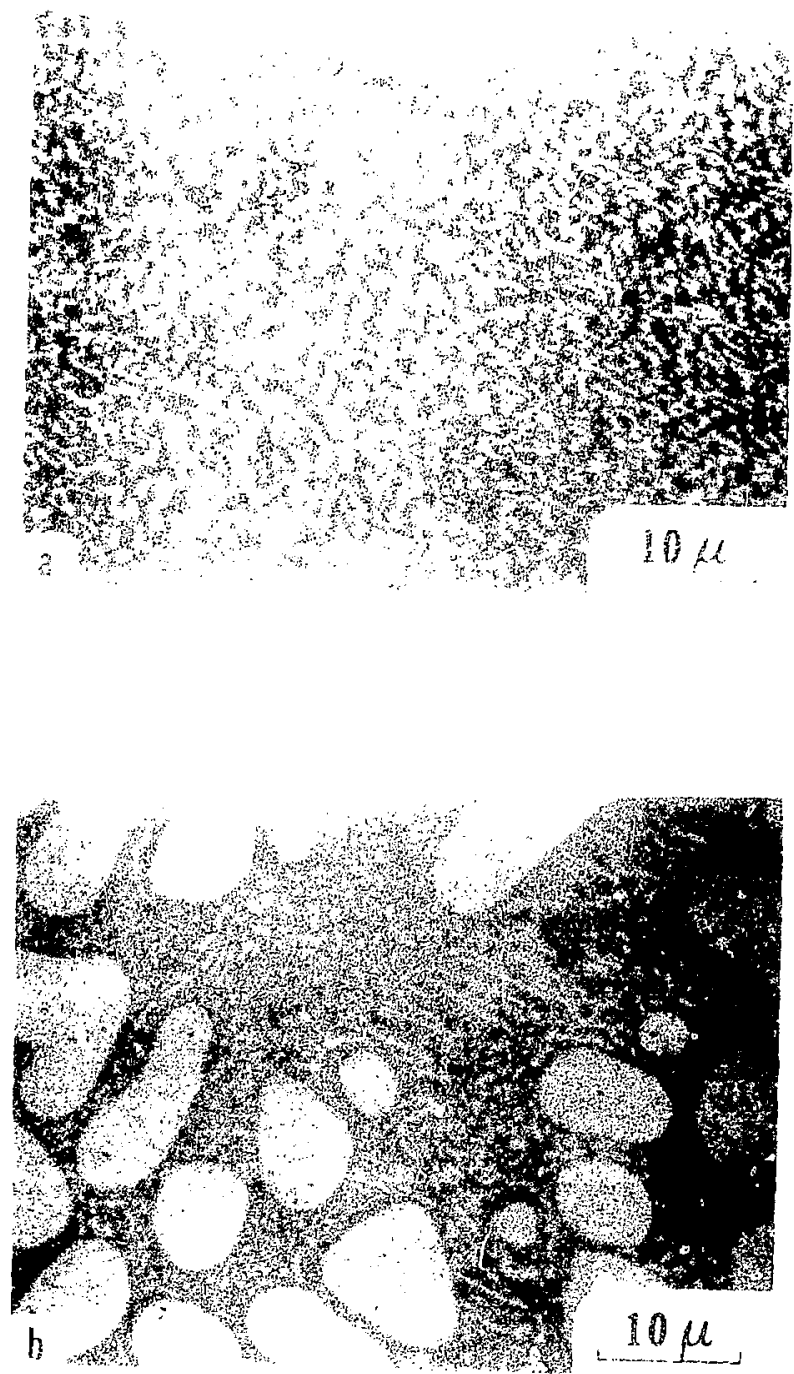


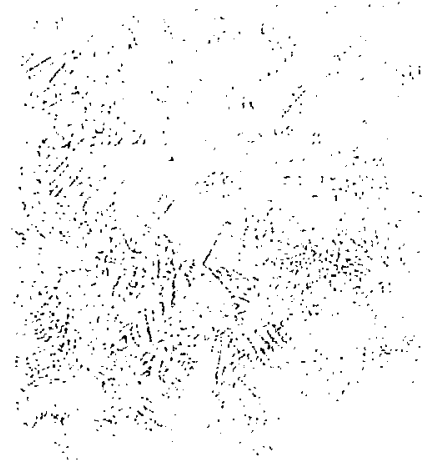



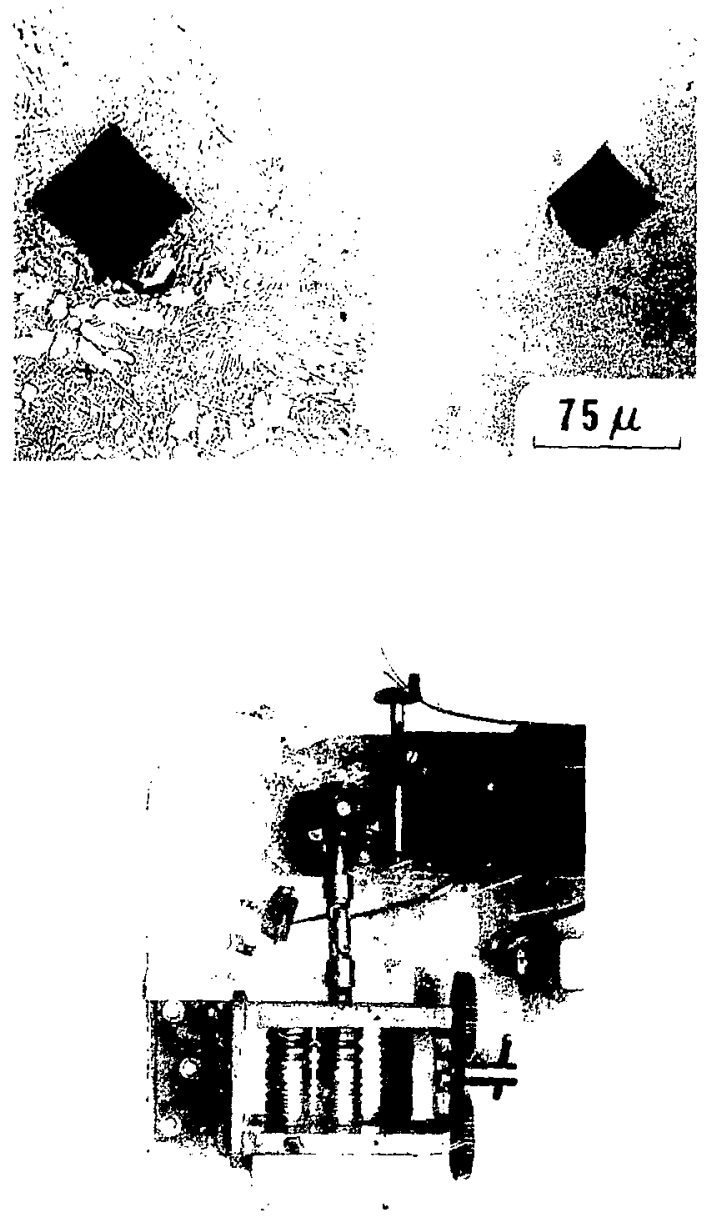


\section{HOT-WIRE-DRAWING APPARATUS}

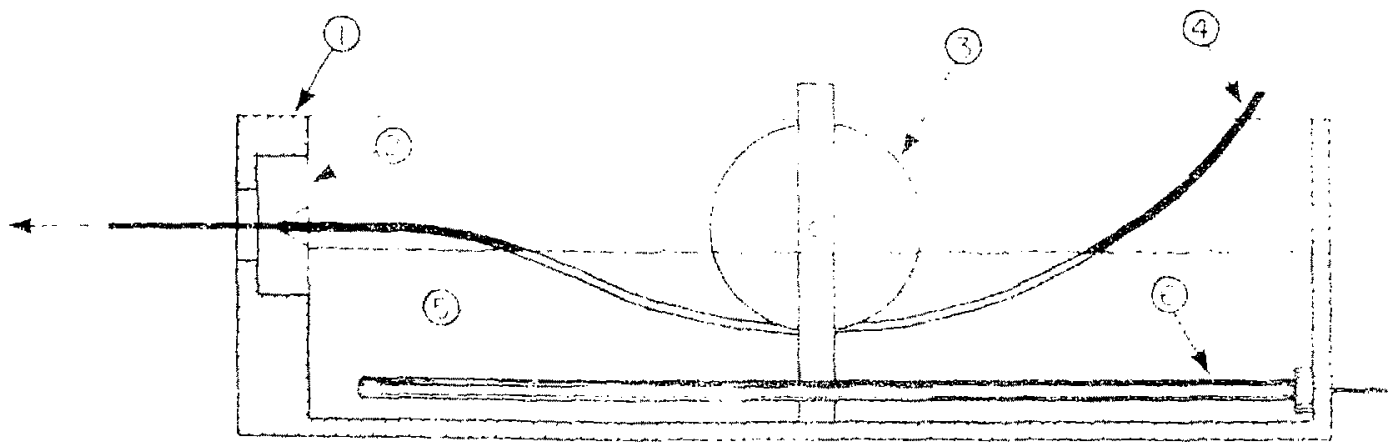

$x+\cdots$ 

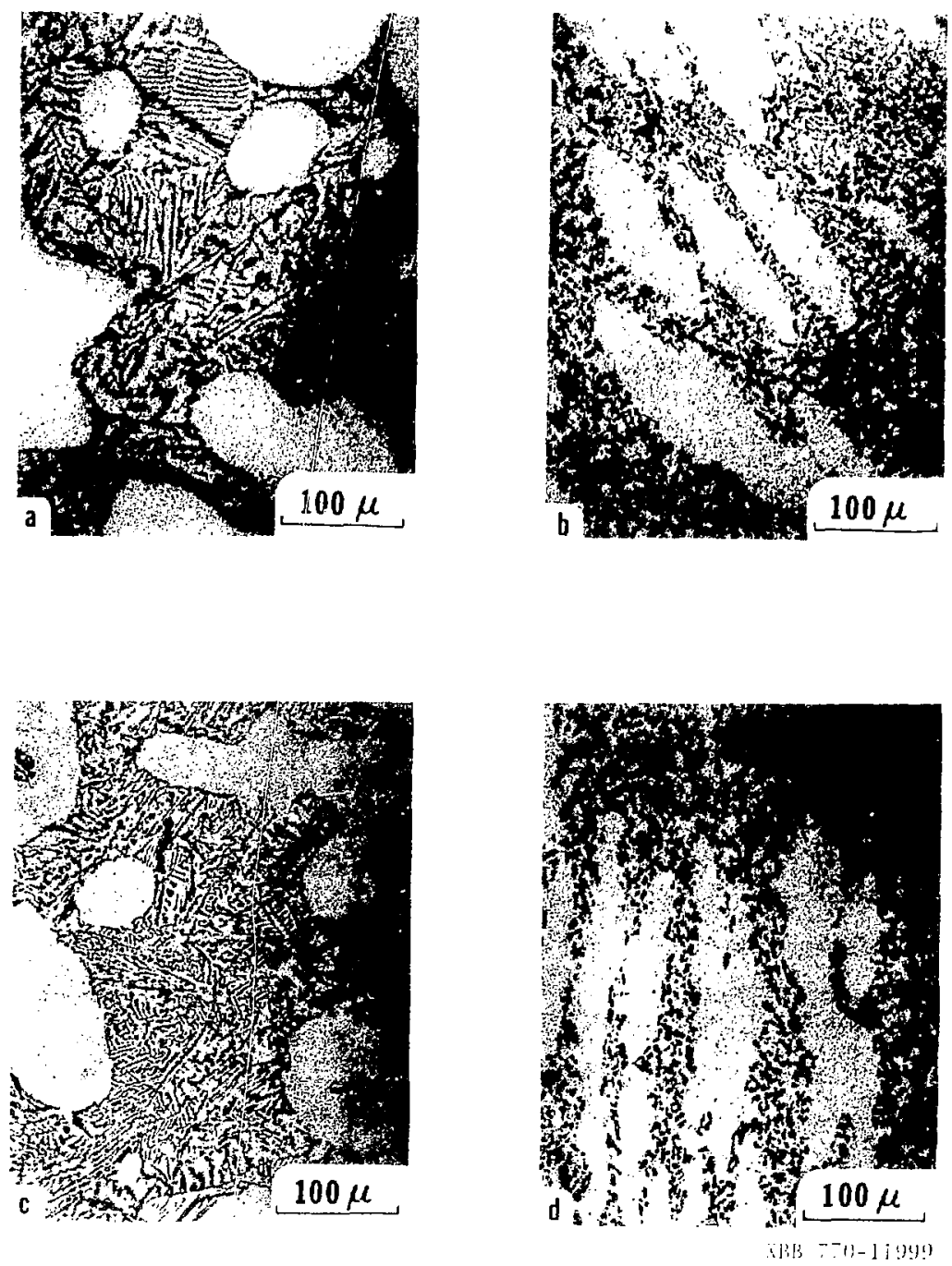


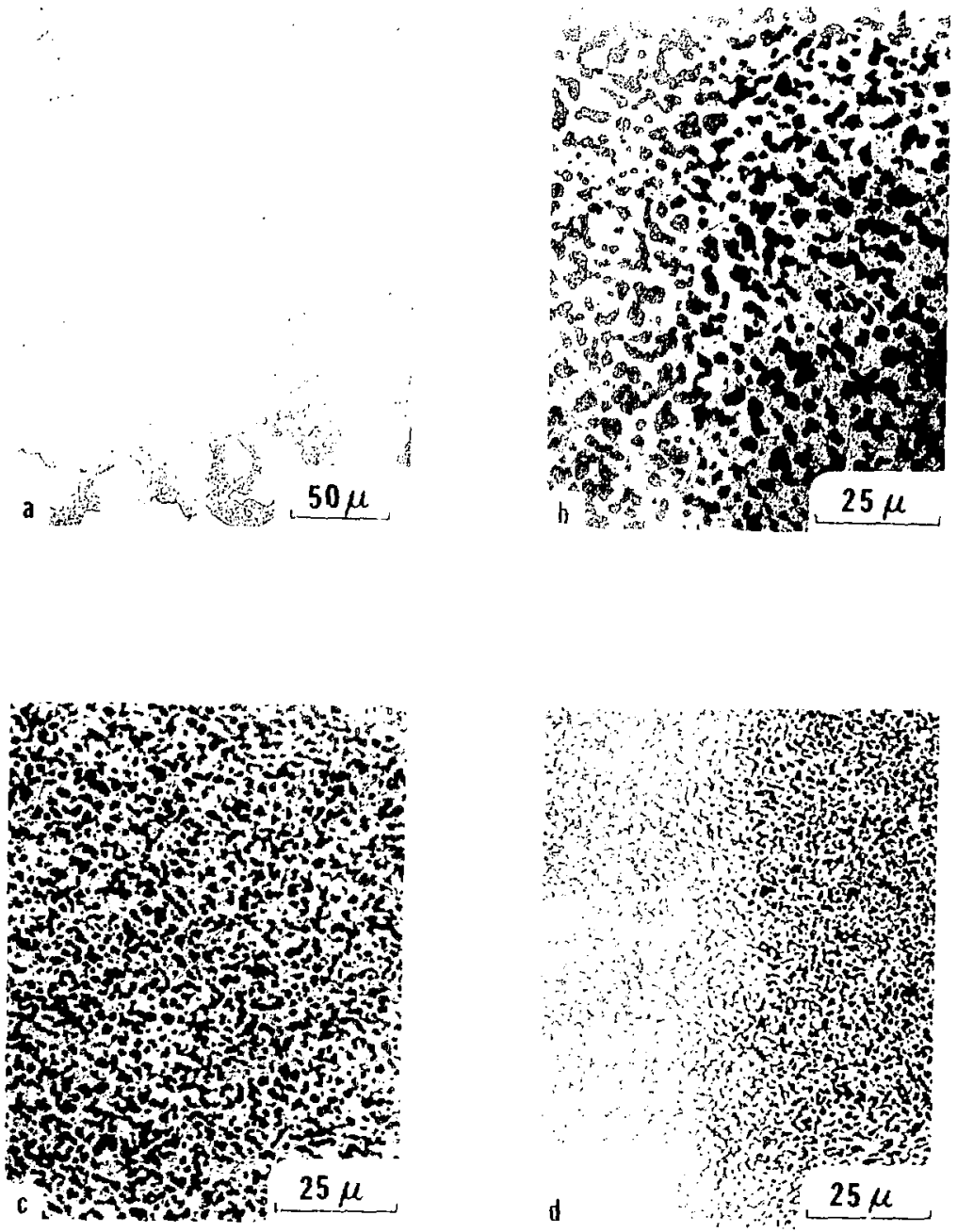

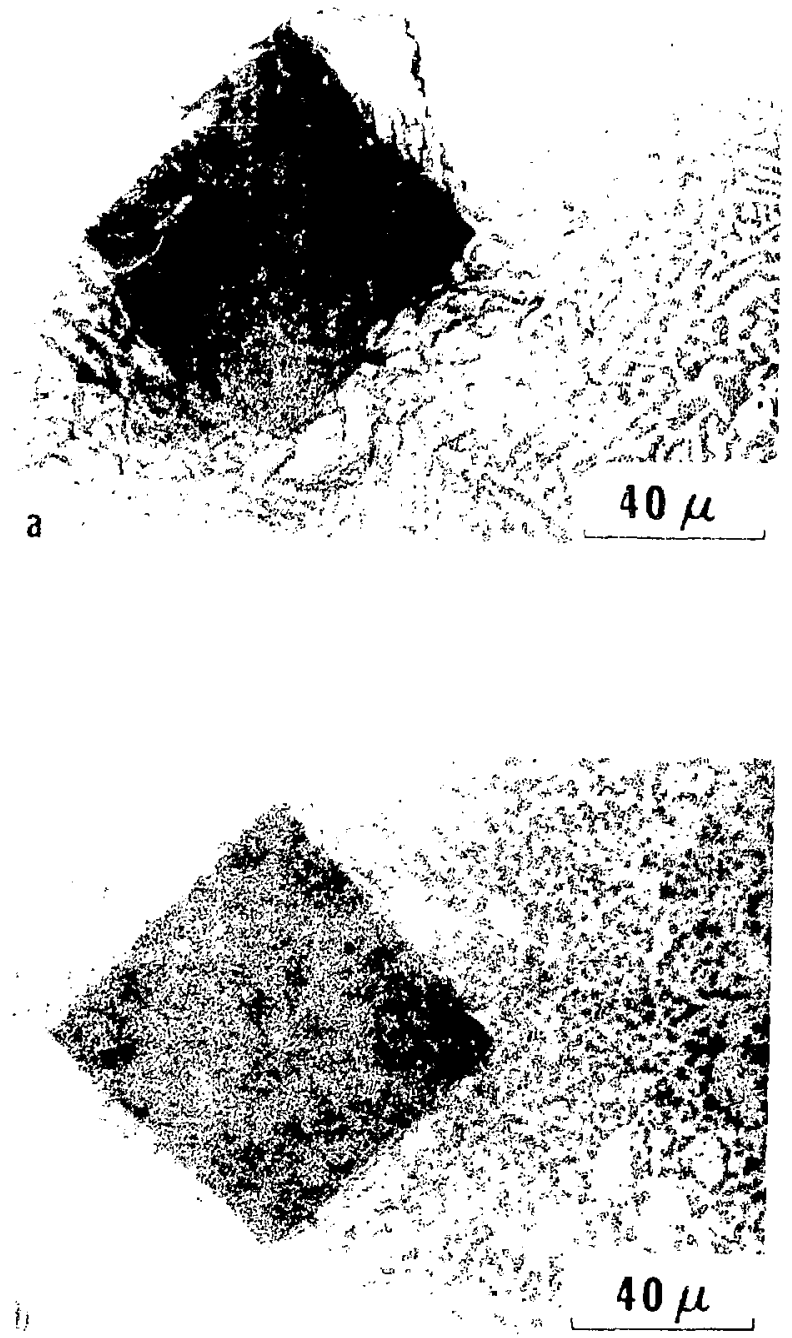


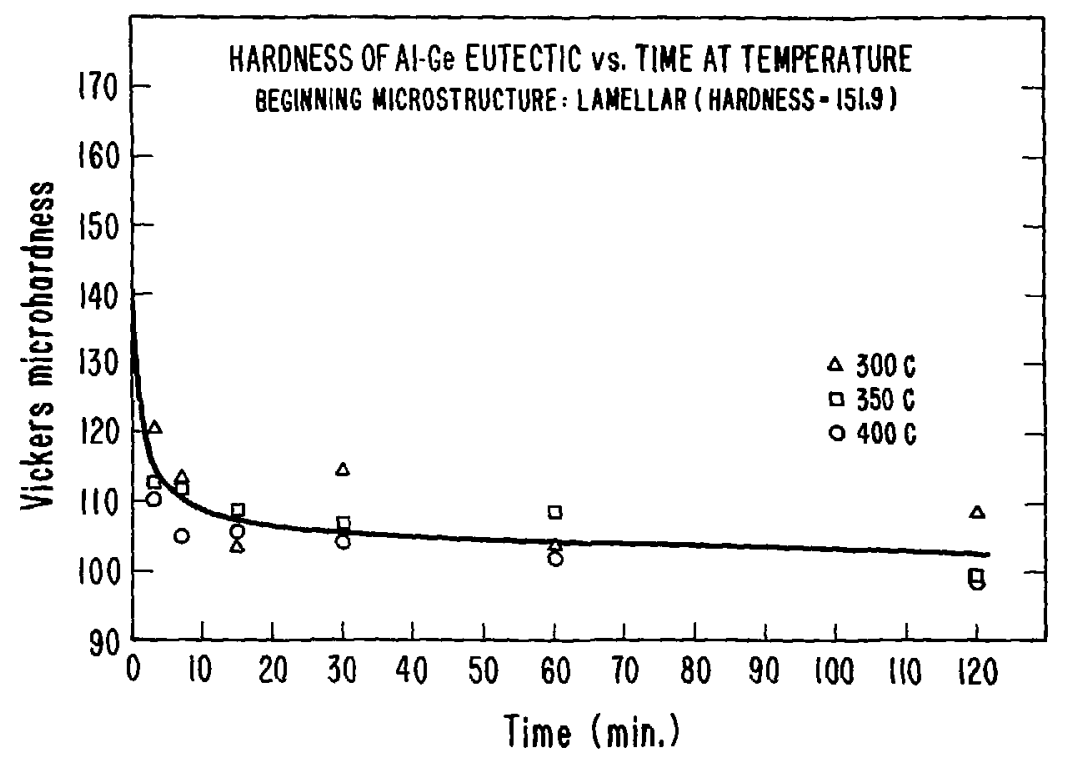




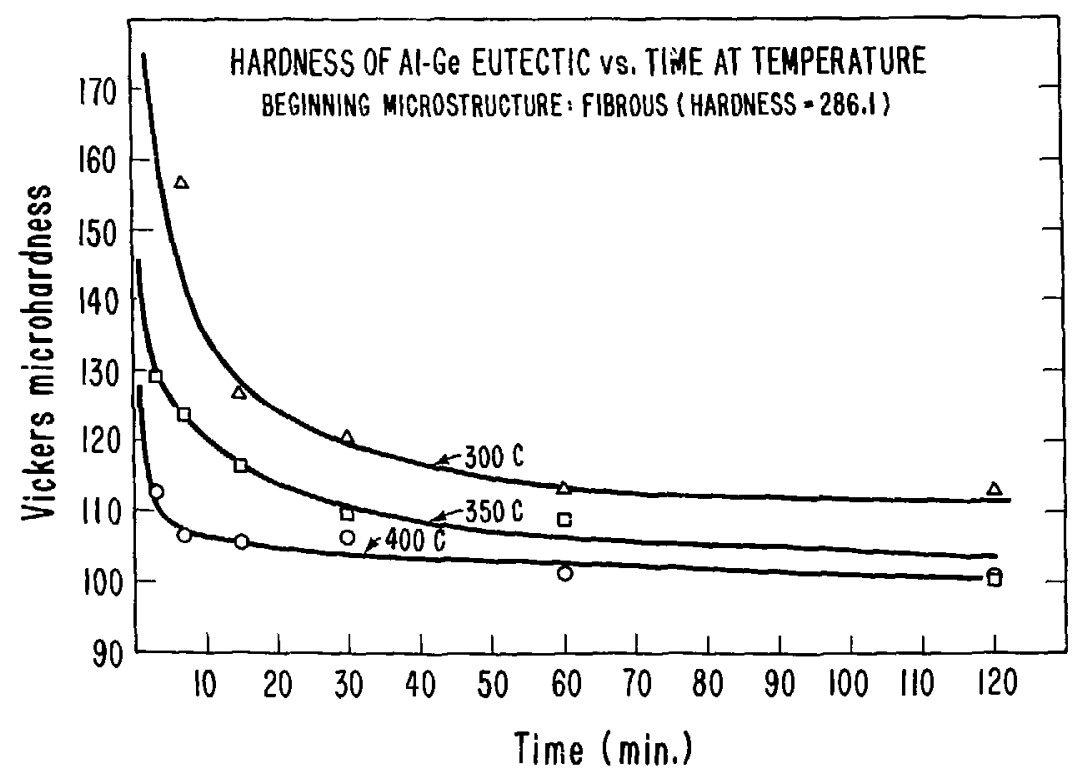

X日L7711-11354

Fig. 13 


\section{0-30 Atomic \% Al-Ge \\ Form Rolled Ho: - 50\% Reduction}

$400 \mathrm{C}$

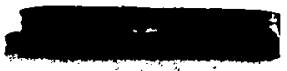

$350 \mathrm{C}$

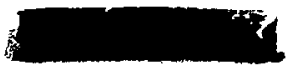

$300 \mathrm{C}$

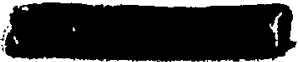

$250 \mathrm{C}$

$250 \mathrm{C}$

(after1 h.@350 C)

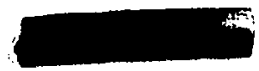

$350 \mathrm{C}$

(clad in $\mathrm{Cu}$ )

Fig. 14 


\section{0-20 Atomic \% Al-Ge \\ Form Rolled Hot - $50 \%$ Reduction}

$400 \mathrm{C}$

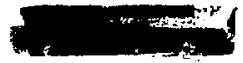

$350 \mathrm{C}$

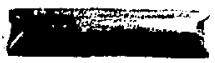

$300 \mathrm{C}$

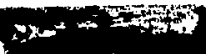

$250 \mathrm{C}$

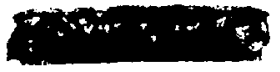

$250 \mathrm{C}$

(after1 h.@330 C)

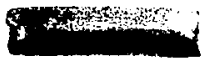

- $250 \mathrm{C}$

(after $\frac{1}{2}$ h. @ 330 C)

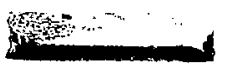




\section{0-30 Atomic \% Al-Ge}

Form Rolled @ $350 \mathrm{C}$ to Various Reductions

$31.8 \%$

$49.6 \%$

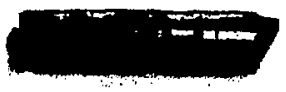

$59.3 \%$

$66.9 \%$

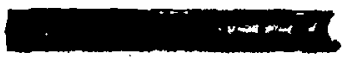

$69.4 \%$

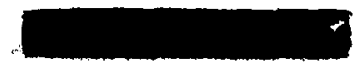

XBB 770-12183

$75.0 \%$

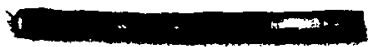

Fig. 16 
80-20 Atomic \% Al-Ge

Form Rolled@350 C to Various Reductions

$31.8 \%$

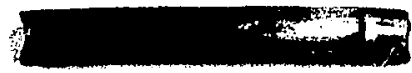

$49.6 \%$

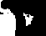

(4)

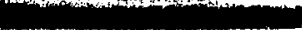

$59.3 \%$

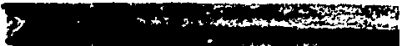

$66.9 \%$

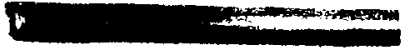

$69.4 \%$

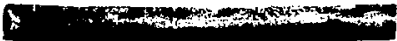

$75.0 \%$

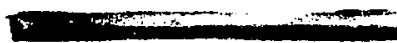



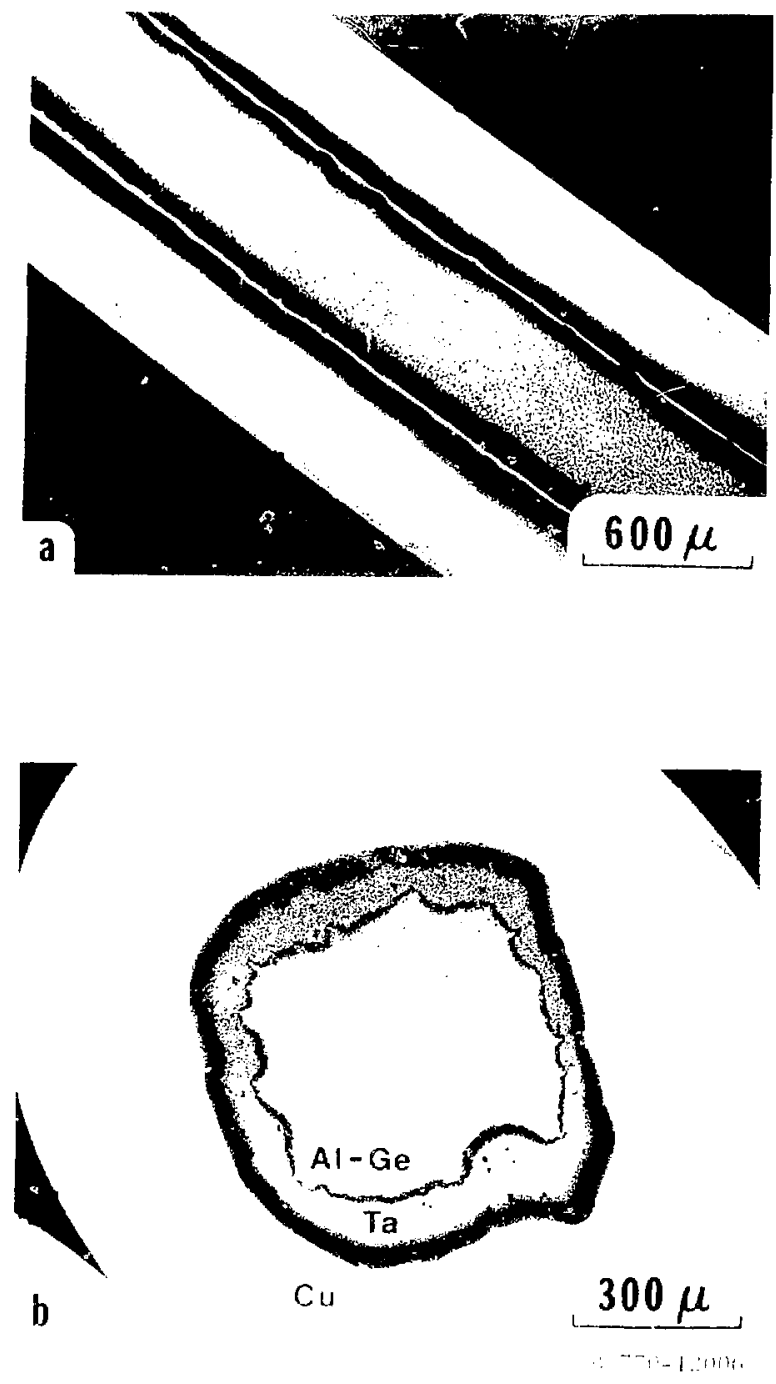


$$
70-30 A 1: \cdots, \quad \therefore:-20
$$
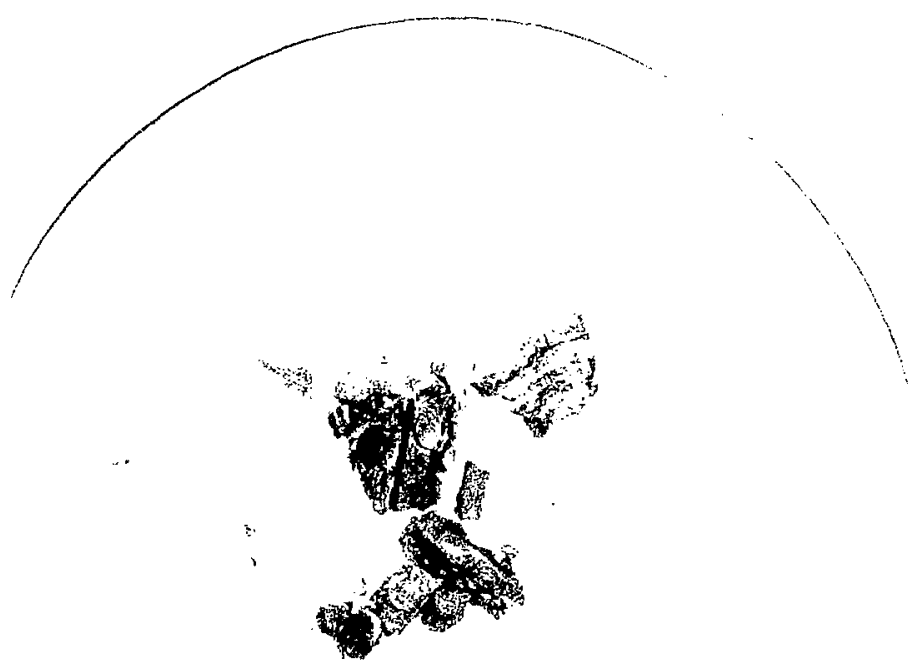
CONGEPTUAL FABRICATION OF Nb-AI-Ge MULTIFLAMENTARY WIRE

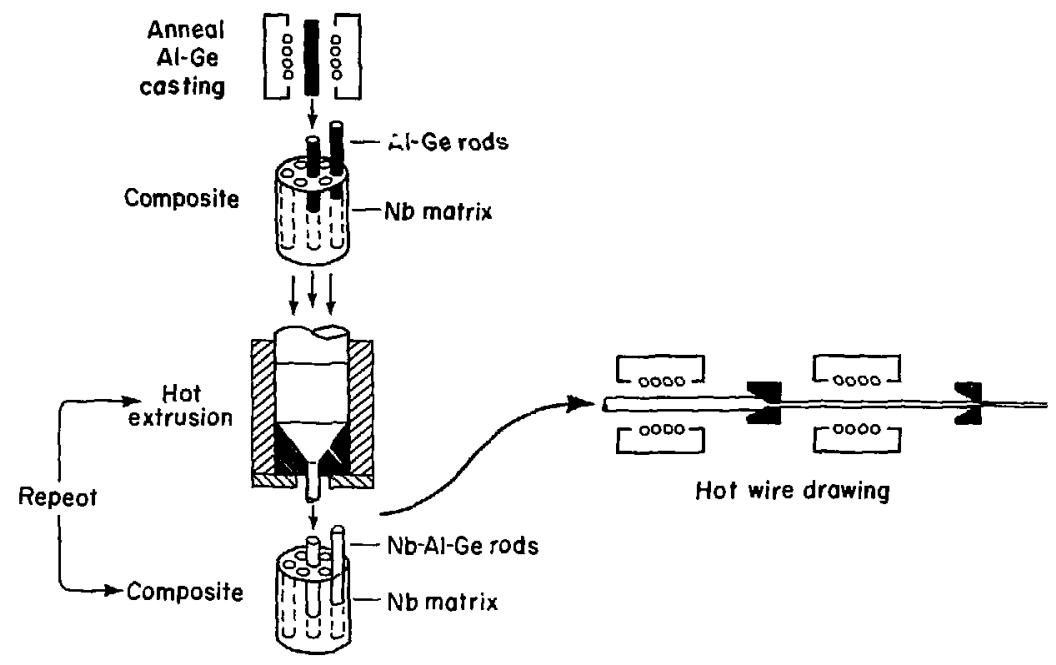

